\title{
Terceirização e saúde do trabalhador: Uma revisão da literatura nacional
}

\author{
Outsourcing and worker health: A review of the national literature \\ Subcontratación y salud del trabajador: Revisión de la literatura nacional
}

\author{
Cassio Adriano Braz de AQUINO1,a \\ Iratan Bezerra de SABÓIA ${ }^{\mathrm{b}}$ \\ Pamella Beserra de MELO ${ }^{a}$ \\ Tainã Alcântara de CARVALHO \\ Veronica Morais XIMENES ${ }^{a}$ \\ Universidade Federal do Ceará, Fortaleza, CE, Brasila ${ }^{\text {, }}$ Universidade Federal do Ceará, Sobral, CE, Brasil ${ }^{\text {b }}$
}

ResumO Objetiva-se discutir a vulnerabilidade no mundo laboral a partir da terceirização e da saúde do trabalhador por meio de uma revisão da literatura dos trabalhos científicos nacionais produzidos entre 2010 e 2015 nas bases de dados da SciELO, BVS-Psi, Banco de Teses e Periódicos CAPES, com os seguintes descritores: trabalho, terceirização e saúde. Para tal, consideraram-se as categorias: quantidade de autores, região do veículo de publicação e dos autores, natureza da pesquisa, tipo de tratamento de dados, área do conhecimento da publicação e área de formação dos autores. A partir do contexto de precarização no qual se insere grande parte dos trabalhadores, foi possível perceber o tratamento dado ao tema da terceirização, entendendo-a como processo que tomou grandes proporções na vulnerabilização do trabalho, impactando na saúde do trabalhador. A quantidade de publicações está aquém da relevância concedida à terceirização e de sua relação com a saúde do trabalhador. Destaca-se que o Sudeste concentra o maior número de publicações (78,78\%), como também de autores provenientes de instituições de ensino dessa região (78,94\%). Percebeu-se que a maioria dos textos $(68,42 \%)$ se deteve na análise qualitativa dos dados. Além disso, é na área da Saúde Coletiva que os artigos se concentram mais, ao passo que apenas dois foram publicados em periódicos na área da Psicologia. Dessa forma, busca-se destacar não apenas o caráter da produção acadêmica sobre o tema da terceirização em consonância à categoria saúde, mas expor a participação da teoria da Psicologia ao tema, creditando a devida importância aos estudos multidisciplinares. Palavras-chave:

Saúde do trabalho; terceirização; vulnerabilidade.

\section{Abstract}

The objective is to discuss vulnerability in the working world based on outsourcing and worker health, through a literature review of Brazilian scientific papers between 2010 and 2015 in the databases of SciELO.br, BVS-Psi, and CAPES Theses and Periodicals, with the following descriptors: work, outsourcing, and health. To this end, the categories considered were: number of authors, publishing vehicle and author region, nature of the research, type of data handling, knowledge area of the publication, and degree areas of the authors. Viewed from the context of insecurity, which pertains to most of the workers, the treatment given to the issue of outsourcing could be seen, understanding it as a process that took on grand proportions in bringing vulnerability to work, having an impact on worker health. The number of publications falls short given the relevance of outsourcing and its relationship to worker health. It is noteworthy that the Southeast has the largest number of publications (78.78\%), as well as of authors from educational institutions of this region (78.94\%). It was noted that most of the texts $(68.42 \%)$ were confined to qualitative data analysis. Moreover, it is in the area of public health that the articles focus more, while only two were published in journals in the psychology field. We intend to not only highlight that the academic production on the subject of outsourcing is in line with the health category, but also to expound on the involvement of psychology with that theme, assigning due importance to multidisciplinary studies. Keywords:

Worker's health; outsourced services; vulnerability.

\footnotetext{
Endereço para correspondência: Universidade Federal do Ceará, Centro de Humanidades, Av da Universidade, 2762, Benfica, Fortaleza, CE, Brasil 60020-180. Email: brazdeaquino@gmail.com
} 
Este estudio objetiva discutir la vulnerabilidad en el mundo laboral a partir de la subcontratación y de la salud del trabajador. Para ello, se ha hecho una revisión bibliográfica de los trabajos científicos nacionales publicados entre 2010 y 2015 en las bases de datos de la SciELO, BVS-Psi, Banco de Tesis y Periódicos CAPES, con los siguientes descriptores: trabajo, subcontratación y salud. Para tanto, se tuvieron en cuenta las categorías: cantidad de autores, región del medio de publicación y de los autores, naturaleza de la investigación, tipo de tratamiento de datos, área de conocimiento de la publicación y área de formación de los autores. A partir del contexto de precarización en el que se insiere gran parte de los trabajadores, fue posible comprender el tratamiento dado al tema de la subcontratación, entendiéndola como un proceso que tomó grandes proporciones en la vulnerabilidad del trabajo, causando impacto en la salud del trabajador. La cantidad de publicaciones es inferior a la relevancia atribuida a la subcontratación y a su relación con la salud del trabajador. Cabe destacar que el Sureste detiene el mayor número de publicaciones (un 78,78\%), así como de autores provenientes de instituciones de enseñanza de esa región (un 78,94\%). Se observó que la mayoría de los textos (un 68,42\%) se detuvo en el análisis cualitativo de los datos. Además de eso, es en el ámbito de la Salud Colectiva que los artículos más se concentran, mientras que solamente dos fueron publicados en periódicos en el campo de la psicología. De esta manera, se busca destacar no sólo el carácter de la producción académica sobre el tema de la subcontratación en consonancia con la categoría salud, sino también exponer la participación de la teoría de la psicología al tema, dando la debida importancia a los estudios multidisciplinares.

Palabras-clave:

Salud del trabajo; subcontratación; vulnerabilidad.

A ideia da centralidade do trabalho é amplamente discutida na literatura, desde as teorias de Weber (2015), com a reformulação que a positivação do trabalho trouxe, até a sociologia do tempo, que discute e atesta a primazia do tempo de trabalho sobre os outros tempos sociais (Dumazedier, 2008; Munnè, 1990; Pronovost, 2011). Inúmeros autores referem que ainda hoje se vive em uma sociedade baseada no trabalho. Autores marxistas assumem que essa atividade continua atuando largamente no delineamento da vida, considerando, sobre isso, a dupla perspectiva marxiana do trabalho. Mesmo pensadores como Elias (1994) e Lipovetsky (2005), que retratam a sociedade de consumo, não conseguem escapar da lógica de que é pelo trabalho e no trabalho que o consumo se concretiza, pois, por um lado, é pelo trabalho que a mercadoria é criada e, por outro, é nele que a condição material de acesso ao consumo se efetiva.

Entretanto, os efeitos de uma sociedade baseada no consumo e centrada no trabalho não passam impunes pelos sujeitos que vivem sob essa lógica. Sob o sistema capitalista, os trabalhadores se veem cada vez mais cooptados por processos como a precarização e a flexibilização, os quais alteram sua relação com o trabalho e desestabiliza esse núcleo não só produtivo, mas também identitário, que é o ato de trabalhar.

Submetidos a perdas sucessivas de direitos e seguridades, os trabalhadores vêm se ajustando a um mercado que, por um lado, encolhe em números de vagas de emprego e, por outro, incha as fileiras de subempregados e não trabalhadores, que se tornam órfãos de uma atividade regularizada em função do desemprego estrutural alavancado pela substituição do trabalho vivo pelo trabalho morto e pelas novas formas de gestão nas empresas (Antunes, 1999). Nesse contexto, as classes mais vulneráveis socialmente e que dependem das intervenções do Estado para se manter dentro de limites de renda para a sobrevivência também fazem parte da camada da população mais vulnerável em termos de trabalho "digno", ou seja, aquele que apresenta seguridade mínima e que proporciona uma inserção estável no mercado, garantindo uma renda mínima também estável que subsidie o trabalhador frente à vulnerabilidade social - entendida por Castel (1997) como a "conjunção da precarização do trabalho e da fragilização dos apoios relacionais" (p.30).

Um dos fatores a ser destacado é a terceirização como processo de vulnerabilização de uma parcela significativa da população, que não encontra um caminho de inserção plena no mercado de trabalho, acarretando, de forma concomitante, uma ausência de acesso a diversos benefícios sociais e bens materiais que a condição de trabalho pleno pode permitir. Assim, essa população também se torna vulnerável em diversos outros aspectos, como no acesso à informação, à educação e a possibilidade de socialização. Esses fatores, por sua vez, limitam seu ingresso ao mercado de trabalho, alimentando de forma dialética o processo de desfiliação (Castel, 2008). Esse quadro certamente impacta na saúde do trabalhador em diversos aspectos, entre eles sua saúde mental, assim como no acesso ao próprio sistema de saúde. É justamente sobre esse panorama que este artigo procura incidir. 
O tema da precarização e flexibilização do trabalho é excessivamente amplo, então, optou-se por restringilo à terceirização, entendendo esse fenômeno como um dos grandes aportes dos dois processos. Soma-se a isso a atualidade do tema com a tramitação da Lei da Terceirização (que torna viável a expansão do trabalho terceirizado a qualquer atividade dentro das empresas) pelas instâncias legislativas e executivas do país, e pela recente decisão pela constitucionalidade das Organizações Sociais promulgada pelo Supremo Tribunal Federal. Dessa forma, dada a importância do tema e seu impacto na sociedade, este artigo pretende fazer um levantamento das publicações nacionais, nos últimos cinco anos, nas principais bases de dados nacionais: SciELO, BVSPsi, Periódicos e Banco de Teses CAPES (Coordenação de Aperfeiçoamento de Pessoal de Nível Superior), estabelecendo critérios de inclusão e exclusão que serão discutidos em nosso percurso metodológico.

\section{Desestruturação do mercado de trabalho e impactos à saúde do trabalhador}

Como resposta à crise global, o mundo do trabalho passou por um processo de reestruturação produtiva com a transição do modelo fordista-taylorista para o modelo toyotista, caracterizado pela acumulação flexível e pelo enxugamento das fábricas, fatores mais adequados às novas exigências do mercado. Tal processo ocorreu por meio de novas formas de intensificação e controle do trabalho, realizados por meio da redução de efetivos e de custos, do modelo de produção just in time, da criação de uma nova cultura nas organizações - o kaizen - e do enfraquecimento dos sindicatos (Navarro \& Padilha, 2007).

Antunes (1999) mostra que a reestruturação produtiva gera novas formas de vínculo laboral precárias, entre elas a terceirização, que estão relacionadas aos objetivos últimos do capital para geração de mais-valia. A terceirização surge para flexibilizar a força produtiva das empresas em crise, expandindo-se, todavia, a diversas atividades, atingindo não apenas a esfera dos serviços ou das atividades-meio (limpeza, vigilância, manutenção), mas chegando a despontar entre as atividades-fim, como nos setores de tecnologia da informação, bancário, automobilístico e de telefonia (Borsói, 2011).

A terceirização é entendida como uma relação de vínculo trabalhista em que uma empresa/empregador contrata um terceiro para prestar serviços em sua empresa. Tal associação é marcada por uma relação de trabalho vulnerável, pela fragilidade dos direitos trabalhistas, de defesa e segurança (Marcelino, 2008). Conforme Marcelino (2008):

A terceirização se inscreve hoje como uma das práticas de gestão do trabalho que visa um processo de descentralização das empresas. Ela pode se dar de diferentes formas: trabalho domiciliar, empresas fornecedoras de componentes, serviços e, até mesmo, força de trabalho para a própria planta produtiva da empresa contratante. (p. 123)

No Brasil, a terceirização ganhou força na década de 1990, durante o governo Collor - junto à intensificação da inserção do modelo de produção brasileiro aos ditames do toyotismo -, com a expansão neoliberal no país, possibilitada pela abertura comercial ao mercado internacional, que iniciou o processo de privatizações de empresas públicas e de redução do papel do Estado. Nesse contexto, a flexibilização na administração pública iniciou-se como parte desse cenário maior, principalmente diante da crise econômica que se vivenciava, cuja proposta neoliberal de solução passava por limitar a atuação do Estado na economia, reduzindo seu papel social, e a conceder à atuação do mercado o papel de instituição determinante ao acesso de grande parte dos bens e serviços sociais. Buscou-se, assim, a implementação de mecanismos de mercado na gestão pública, voltados para a administração ágil, menos burocrática, com foco na sociedade como "cliente" (Aquino, Moita, Correa, \& Souza, 2014).

Sendo uma das estratégias utilizadas na precarização e flexibilização laboral, a terceirização cria um cenário de vulnerabilidade ao trabalhador que pode repercutir em diversas esferas. Como dito anteriormente, Castel (1997) delimita a vulnerabilidade como um ponto de interseção entre uma frágil rede relacional e uma situação de trabalho precário, chegando a essa definição ao estabelecer uma relação íntima entre a inserção social e a conjuntura laboral a qual o sujeito está inserido.

Em seu artigo, Castel (1997) delimita três eixos de vínculo laboral e filiação social a partir da perspectiva da centralidade do trabalho na vida contemporânea: (a) o trabalho estável, que gera e alimenta laços sociais fortes; (b) o trabalho precário, que faz referência a laços sociais mais fragilizados; e (c) o não trabalho, que se ligaria a um isolamento social. No primeiro, são apresentadas quatro zonas sociais criadas de acordo com os 
três eixos: o primeiro geraria a zona de integração social; o segundo seria a zona de vulnerabilidade (nesse caso, a que mais interessa neste estudo); o terceiro eixo daria origem a duas zonas: a de assistência e a de desfiliação. É importante destacar que, para o autor, os sujeitos que estão na zona de vulnerabilidade são aqueles em uma situação crítica, pois os pertencentes às duas últimas zonas já dependem da intervenção estatal (no caso da assistência) ou vivem à margem da sociedade (desfiliados), já existindo para estes aparatos estatais de apoio.

No entanto, aqueles em situação de vulnerabilidade vivem em uma pseudoestabilidade, pois, devido a suas condições estruturalmente instáveis (não ter reserva financeira, serem totalmente dependentes dos níveis de empregabilidade, não estarem amparados pela ampla legislação, etc.), estão sujeitos à volatilidade do sistema econômico e, em caso de desequilíbrio, vão para as últimas duas zonas (assistência e desfiliação).

Ora, é justamente na precarização do trabalho que o laço social começa a se fragilizar, e a terceirização é uma das características e estratégias desse processo. Assim, o aumento da terceirização geraria não apenas um ônus ao Estado no sentido de criar novas redes de assistência ou de ampliar as já existentes; mas principalmente impactaria o sujeito, que, vivendo um laço social frágil (desde as relações pessoais até suas condições de moradia), passa a viver um contexto de pressão psicológica que pode gerar agravos a sua saúde mental, como depressão e síndrome de burnout. Nesse sentido, Lima, Barros e Aquino (2012) ressaltam as consequências da intensificação do trabalho diante da precarização, apontando para um esgotamento físico e psíquico do trabalhador. Isso pode ser percebido pelo aumento na incidência de estresse, de acidentes no trabalho, de doenças ocupacionais expressas em modos de sofrimento, como depressão, transtorno psicossomático, transtorno de ansiedade, além do aumento do absenteísmo em decorrência de lesões por esforços repetitivos/distúrbios osteomusculares relacionados ao trabalho (LER/DORT). Os autores concluem que o adoecimento repercute sobre a vida laboral, social e familiar do trabalhador.

Essa temática ganhou maior visibilidade do público em geral quando o deputado e empresário da indústria alimentícia Sandro Mabel (PMDB-GO) lançou o Projeto de Lei 4.330/2004 conhecido como "PL da Terceirização" em 2004, que visa regulamentar a prestação de serviços via subcontratação. O projeto foi votado pela Câmara dos Deputados em abril de 2015, tendo sido aprovado e enviado para o Senado, mesmo diante de intensa resistência e mobilização popular e das centrais sindicais contra a aprovação.

Nesse sentido, em entrevista concedida ao Esquerda Diário, Antunes (2015) afirma que o PL, em vez de regulamentar 12 milhões de pessoas, vai desregulamentar, vulnerabilizar e precarizar 30 milhões de trabalhadores. Segundo o autor, a falácia de regulamentar o trabalho terceirizado e de que as empresas poderão se concentrar em seu negócio principal e melhorar a qualidade dos serviços e produtos é usada para escamotear as reais intenções do referido projeto na redução dos custos, na quebra dos direitos dos trabalhadores e na fragmentação e desorganização da classe trabalhadora.

Um estudo recente da Secretaria Nacional de Relações de Trabalho e do Departamento Intersindical de Estatística e Estudos Socioeconômicos (2014) mostra que trabalhadores terceirizados recebem remuneração média inferior a dos trabalhadores com vínculo efetivo (24,7\%), têm maior jornada semanal de trabalho (7,5\%) e menor tempo de permanência no emprego (53,5\%), aumentando, assim, a rotatividade e a dificuldade em estabelecer o nexo causal em casos de adoecimento decorrentes do trabalho, além de serem vítimas de maior número de acidentes laborais (47\%). O estudo indica, ainda, que os terceirizados estão mais sujeitos a trabalhos análogos ao trabalho escravo até aproximadamente seis vezes mais que os trabalhadores contratados. As ações sindicais em torno da terceirização totalizam 37\%, com cláusulas referentes à extensão dos benefícios aos terceirizados, à responsabilidade solidária ou subsidiária pelos compromissos não honrados pelas empresas terceiras, legalmente constituídas, ao acesso às informações dos contratos de terceirização e outras garantias sindicais, as quais os trabalhadores terceirizados, pela fragilidade do vínculo, muitas vezes não têm capacidade de mobilização coletiva (SRT \& DIEESE, 2014).

Nesse contexto, o trabalhador é afetado de diversas formas, inclusive com impactos em sua saúde mental. Foi a partir desse aspecto que uma nova área de estudo e intervenção se desenvolveu, a psicologia voltada para a saúde do trabalhador, que busca um conhecimento interdisciplinar e que, a partir de uma visão crítica, supera a concepção biologicista sobre os agentes patológicos que provocam o adoecimento no trabalho (Lacaz, 2007).

A psicologia voltada para a saúde do trabalhador reconhece o processo de saúde-doença em sua complexidade e historicidade. Assim, na análise do trabalho, são considerados os processos de trabalho, bem como as condições as quais os trabalhadores se encontram submetidos (Minayo-Gomez \& Thedim-Costa, 1997). Desse modo, toma-se o trabalho como principal organizador da vida social, considerando-se os trabalhadores 
detentores de conhecimento e saber sobre sua prática, de modo que devem ser protagonistas nas transformações dos contextos laborais.

Para Canguilhem (2009), a concepção de saúde está além de um saber restrito a especialistas, mas vinculase ao modo como os próprios sujeitos a vivenciam:

[...] um conceito vulgar, alheio ao campo do saber objetivo e que estaria ao alcance de todos. Nesta forma de pensar, a saúde não é propriedade de especialistas e, embora não possa prescindir desses saberes, deve incorporar como dimensão a experiência do corpo e suas referencias de dor e prazer do ponto de vista de quem as vive. (Lima, 2011, p. 321)

Destaca-se a concepção de saúde a partir de uma perspectiva que considera aspectos sociais, afetivos, econômicos, objetivos e subjetivos que interferem na produção de vida/saúde dos indivíduos. Assim, segundo Canguilhem (2009), o conceito de "saúde" é concebido como potência de ação sobre o mundo, como capacidade normativa, de inventar novas normas que questionem o que está posto, principalmente diante do contexto de constante negação de suas singularidades, necessidades e potencialidades no qual o trabalhador se insere, o que homogeneiza, vulnerabiliza, fragmenta e exclui grande parcela da população do trabalho como meio de realização e reconhecimento.

Estudos, como o de Minayo-Gomez e Brant (2011), apontam para a diversidade de abordagens teóricometodológicas sobre a relação saúde e trabalho, com pesquisas abordando aspectos relativos à saúde mental e do trabalhador, relacionados à subjetividade e/ou ao trabalho e suas transformações. Autores como Dejours (1999) e Lima et al. (2012) afirmam existir uma relação entre precarização e adoecimento psíquico resultante da intensificação do trabalho ou das condições laborais as quais os sujeitos inseridos nesses novos vínculos de trabalho se submetem. Estudos apontam que esses adoecimentos psíquicos são causas de afastamento do trabalho e ingresso em um não trabalho pautado na assistência do Estado.

Torres, Chagas, Moreira, Barreto e Rodrigues (2011) apontam que pessoas afastadas do trabalho por doenças que as deixam incapacitadas de exercer suas profissões, mesmo que temporariamente, tendem a ter baixa autoestima e isolamento social. Jorge e Bezerra (2004) apontam que trabalhadores excluídos de suas atividades laborais padecem de um significativo sofrimento e que esse não trabalho gera isolamento social, mesmo no seio familiar.

Retomando o conceito de vulnerabilidade de Castel (1997), tem-se uma lógica cíclica: precarização gera sofrimento; esse sofrimento pode causar adoecimento mental, que, por sua vez, leva ao isolamento e ao não trabalho (que também leva ao isolamento); este isolamento gera sofrimento, que retoma ao ponto em que o adoecimento mental pode se instaurar e retomar ao ciclo precarização-sofrimento-adoecimento-isolamento. Dessa forma, é inegável a importância de se estudar essa relação e como ela se estabelece, não apenas no campo teórico, mas sobretudo com pesquisas empíricas que possam dar conta tanto de dados quantitativos quanto qualitativos, como esse processo é vivido pelos trabalhadores e como isso repercute nele e em seu entorno. Se teórica e empiricamente estudos apontam para essa realidade, ela deve ser estudada de forma aprofundada, principalmente em um cenário em que a legislação busca abarcar de forma ampla a regulamentação dessa prática. Assim, considera-se pertinente associar saúde, trabalho e terceirização, diante da escassez de estudos que abordem esses três fatores inter-relacionados (como se verá adiante), e como uma possibilidade de compreender a vulnerabilidade a qual os trabalhadores encontram-se submetidos.

\section{MÉTODO}

Para a realização das proposições deste artigo, adotou-se o método de revisão sistemática de publicação, como apresentado por Landeiro, Pedrozo, Gomes e Oliveira (2011). Este estudo se propõe a realizar levantamento e análise das publicações das principais bases de dados abertas do Brasil: SciELO, BVS-PSI e Periódicos e Banco de Teses da CAPES. Esse tipo de pesquisa se caracteriza como survey, que utiliza a pesquisa bibliográfica como fonte de estudo.

Garcia (2014) define a revisão sistemática como um modelo de pesquisa que consiste em "uma revisão da literatura realizada a partir de uma pergunta de pesquisa definida, por meio da qual se busca identificar, avaliar, selecionar e sintetizar evidências de estudos empíricos que atendam a critérios de elegibilidade predefinidos" (p.7). 
O estudo sobre o estado da arte, como também pode ser denominado, centra sua relevância no levantamento sistemático de publicações de grande impacto sobre um determinado tema, por uma dupla vertente: primeiro, traçando um panorama da produção do conhecimento, podendo, com isso, apontar caminhos pouco explorados em determinadas áreas, apesar de sua relevância. Também propicia aos demais pesquisadores um mapeamento de possíveis textos a serem explorados como ponto de partida para futuras pesquisas.

Para atingir esses objetivos foram delimitados como critérios de inclusão as seguintes variáveis: textos produzidos nos últimos cinco anos; em português; no Brasil; que apresentassem no texto os descritores trabalho, terceirização e saúde; e estivessem nas bases de dados supracitadas no período de 2010 a 2015 . Por fim, indo ao encontro do objetivo deste artigo, o escopo utilizado ao ser empregado o termo saúde será analisado, o que auxiliará na obtenção da quantidade final de artigos a serem categorizados. A escolha das bases de dados ocorreu devido ao seu reconhecimento como as maiores do Brasil, gozando de vasto acervo e grande fator de impacto Além disso, foram analisadas as seguintes categorias: quantidade de autores, região do veículo de publicação, região dos autores, natureza da pesquisa, tipo de tratamento de dados, área do conhecimento da publicação e área do conhecimento de formação da graduação dos autores.

O principal intuito da revisão sistemática baseia-se no entendimento sobre o modo de tratamento proposto ao tema da terceirização, entendendo-o, conforme exposto anteriormente, como conceito historicamente constituído e estabelecido no país e que nos últimos anos tomou grandes proporções no processo de vulnerabilização de boa parte da sociedade brasileira, impactando a saúde do trabalhador. Em uma compreensão mais específica, o resultado obtido com a pesquisa de trabalhos científicos deverá demonstrar em que contexto o tema da terceirização está inserido na área da Psicologia.

Não se limitando às questões econômicas, a perspectiva da Psicologia sobre a terceirização e o campo da saúde, com especial enfoque às contribuições da Psicologia Social, insere sobre o tema do trabalho discussões que envolvem desde as novas significações do trabalho ao debate sobre a conceituação de vulnerabilidade social e a expansão deste aos diversos campos da vida nos quais o indivíduo se mostra em situação de fragilidade. Neste caso, identificam-se situações de fragilidade relacionadas aos ativos necessários ao bem viver, tais como os físicos (terra, animais, máquinas, moradia, bens duráveis relevantes para a reprodução), sociais (redes de reciprocidade, confiança, contatos e acesso à informação) e humanos (trabalho como ativo principal e o valor agregado ao mesmo pelos investimentos em saúde e educação, os quais implicariam em maior ou menor capacidade física para o trabalho, qualificação etc.) (DIEESE \& UNICAMP, 2007).

Baseando-se na conceituação multifocal de vulnerabilidade social, na qual a fragilização de vários aspectos da vida se mostra como pressuposto para a classificação do indivíduo na condição de "vulnerabilizado" - inclusive a saúde -, utilizaram-se inicialmente os seguintes termos para a busca: terceirização, trabalho e vulnerabilidade (delimitados ao período em estudo e ao idioma). A busca resultou em apenas 15 artigos (dois constantes no portal da BVS-Psi, que direcionou ao portal LILACS, dois constantes no Banco de Teses da CAPES e 11 em Periódico CAPES), dos quais dois estão presentes em mais de um dos bancos de dados, gerando um total de apenas 13 trabalhos com os termos indicados. Tal resultado demonstra a pouca exploração da temática sobre a vulnerabilidade e o trabalho, talvez pela inserção do primeiro termo entre as termologias econômicas, nas quais, muito presente no debate sobre zonas de pobreza, refere-se à situação de baixos rendimentos. $\mathrm{O}$ resultado diminui para cinco trabalhos ao se considerar o escopo associado à palavra-chave saúde, ligada em sua maioria não a um estudo sobre as consequências do trabalho terceirizado sobre a saúde do trabalhador, mas a um estudo sobre as dificuldades encontradas em áreas específicas da saúde, como saúde pública e saúde coletiva. Mediante a insignificância da amostra anterior, a segunda pesquisa, na qual este trabalho se baseou, foi delimitada pelos termos terceirização, trabalho e saúde em todos os sites citados anteriormente, apresentando resultado mais significativo.

\section{RESULTADOS}

A seguir, na Tabela 1, é listado o resultado discriminado a partir de uma primeira busca baseada no período considerado (de 2010 a 2015), no idioma (português) e no país (Brasil). 


\begin{tabular}{|c|c|c|c|c|c|c|c|c|}
\hline Portal & $\begin{array}{c}\text { Total (palavras- } \\
\text { chave) }\end{array}$ & 2010 & 2011 & 2012 & 2013 & 2014 & 2015 & $\begin{array}{c}\text { Total por critérios } \\
\text { de exclusão (exceto } \\
\text { o escopo do termo } \\
\text { saúde) }\end{array}$ \\
\hline SciELO & 19 & - & 2 & 2 & 3 & - & - & 7 \\
\hline $\begin{array}{l}\text { BVS-Psi } \\
\text { (LILACS) }\end{array}$ & 60 & 7 & 4 & 5 & 4 & 3 & - & 23 \\
\hline $\begin{array}{l}\text { Periódico } \\
\text { CAPES }\end{array}$ & 84 & 4 & 5 & 5 & 16 & 4 & - & 34 \\
\hline $\begin{array}{l}\text { Banco de } \\
\text { Teses da } \\
\text { CAPES }\end{array}$ & 22 & - & 13 & 9 & - & - & - & 22 \\
\hline Total & 187 & 11 & 24 & 21 & 23 & 7 & - & 86 \\
\hline
\end{tabular}

Os valores da primeira coluna demonstram o total de artigos encontrados em cada portal tendo como categoria de filtragem apenas as palavras-chave, desconsiderando, portanto, tanto o idioma quanto o período de publicação dos artigos. A partir do tabulamento dos trabalhos encontrados entre 2010 e 2015 (na coluna Total por critérios de exclusão), percebe-se que sua quantidade (86) está aquém da importância que poderia ser concedida sobre a relação entre o trabalho terceirizado, que gera processos de precarização das condições sociais nas quais o indivíduo se produz, e o processo de vulnerabilização no qual se encontram ao terem seus principais ativos fragilizados, conforme expõe Castel (1997).

A próxima etapa de filtragem, por sua vez, além de levar em consideração os filtros idioma (português) e país (Brasil), baseia-se no escopo ao qual o termo saúde está inserido nos trabalhos encontrados. Conforme exposto anteriormente, a inserção do termo na pesquisa, em alguns casos, pode denotar o estudo sobre o tipo de trabalho (precarizado ou não) dos trabalhadores inseridos no campo da saúde. Essa perspectiva serviu como critério de exclusão dos trabalhos que não se inseriam na pesquisa sobre a terceirização como processo denegritório da saúde do trabalhador.

Depois de aplicar os critérios de exclusão e de retirar os artigos repetidos em mais de uma base de dados, obteve-se o resultado constante na Tabela 2:

TABELA 2 - Total de publicações em português entre 2010 e 2015, publicados no Brasil e com recorte da significação do termo saúde

\begin{tabular}{|c|c|c|c|c|c|c|c|}
\hline Portal & 2010 & 2011 & 2012 & 2013 & 2014 & 2015 & Total \\
\hline SciELO & - & - & 1 & 1 & - & 1 & 3 \\
\hline BVS-Psi (LILACS) & 1 & - & 1 & 2 & 2 & - & 6 \\
\hline Periódico CAPES & - & 2 & - & 1 & - & - & 3 \\
\hline Banco de Teses da CAPES & - & 5 & 2 & - & - & - & 7 \\
\hline Total & 1 & 7 & 4 & 4 & 2 & 1 & 19 \\
\hline Porcentagem & $5,26 \%$ & $36,84 \%$ & $21,04 \%$ & $21,04 \%$ & $10,52 \%$ & $5,26 \%$ & $100 \%$ \\
\hline
\end{tabular}

Nota. Não foi feita uma porcentagem de cada base de dados em relação ao total de publicações encontradas porque as publicações se repetem em algumas delas e, nesse caso, a exclusão foi aleatória em relação a base de dados.

Ao se analisar a Tabela 2, percebe-se que em 2011 as publicações sobre o tema atingiram seu ápice; depois disso, nota-se um decréscimo gradativo no número de publicações. Com a diminuição desde 2011, é provável que se tenha, ao fim de 2015, um número de publicações igual, ou próximo, ao do ano anterior. Ainda assim, destaca-se que duas publicações por ano sobre o tema é uma quantidade muito pequena, dada a sua importância e atualidade. $\mathrm{O}$ agravo à saúde do trabalhador vem crescendo progressivamente frente às novas formas em que o trabalho se apresenta na contemporaneidade e a terceirização é fator relevante para esse fenômeno, principalmente por incidir sobre um fator significativo do emprego: a seguridade. 
Mediante as Tabelas 3, 4 e 5, percebe-se que a multiplicidade de autores poderia cobrir a lacuna criada pela região quando se tem uma rede de pesquisa ampla e que cobre grandes áreas geográficas. No entanto, a concentração de publicações por região é relevante, fazendo a baixa quantidade de artigos publicados no país ser ainda menos significativa pela perspectiva de divisão regional.

TABELA 3 - Divisão por quantidade de autores

\begin{tabular}{|c|c|c|c|c|c|}
\hline Número de autores & SciELO & $\begin{array}{l}\text { BVS-Psi } \\
\text { (LILACS) }\end{array}$ & $\begin{array}{c}\text { Periódico } \\
\text { CAPES }\end{array}$ & Total & $\%$ \\
\hline 1 autor & - & 2 & 1 & 3 & $25 \%$ \\
\hline 2 autores & 1 & 1 & 1 & 3 & $25 \%$ \\
\hline 3 autores & - & 3 & 1 & 4 & $33,33 \%$ \\
\hline 4 ou mais autores & 2 & - & - & 2 & $16,66 \%$ \\
\hline Total & 3 & 6 & 3 & 12 & $100 \%$ \\
\hline
\end{tabular}

Nota. O Banco de Teses da CAPES não foi considerado, pois, por se tratar de um banco de dados de trabalhos monográficos, os artigos têm sempre um único autor.

Além disso, outras duas lacunas percebidas referem-se à região em que o artigo é veiculado e a região do país representada pelas instituições de ensino nas quais os autores se encontram:

TABELA 4 - Divisão por região do veículo de publicação

\begin{tabular}{|c|c|c|c|c|c|c|}
\hline Região & SciELO & $\begin{array}{l}\text { BVS-Psi } \\
\text { (LILACS) }\end{array}$ & $\begin{array}{l}\text { Periódico } \\
\text { CAPES }\end{array}$ & $\begin{array}{c}\text { Banco de } \\
\text { Teses da } \\
\text { CAPES }\end{array}$ & Total & $\%$ \\
\hline Centro-Oeste & - & 1 & - & - & 1 & $5,26 \%$ \\
\hline Nordeste & - & 1 & - & - & 1 & $5,26 \%$ \\
\hline Norte & - & - & - & 1 & 1 & $5,26 \%$ \\
\hline Sudeste & 3 & 4 & 3 & 5 & 15 & $78,94 \%$ \\
\hline Sul & - & - & - & 1 & 1 & $5,26 \%$ \\
\hline Total & 3 & 6 & 3 & 7 & 19 & $100 \%$ \\
\hline
\end{tabular}

Nota. Considerou-se como lugar de publicação para o Banco de Teses da CAPES o local do programa de pós-graduação ao qual o trabalho se vincula.

Não há como determinar a região da filiação institucional do autor quanto à tese defendida, por isso, o Banco de Teses da CAPES não consta na Tabela 5. Ao todo, tem-se 40 autores em 19 trabalhos publicados, sendo 7 deles no Banco de Teses da CAPES. Também não foi feito um levantamento do local de nascimento dos autores (dado que não se tem acesso). Dessa forma, a Tabela 5 refere-se a região representada pelas instituições as quais estão vinculados os autores. Esses dados são importantes porque o objetivo de se verificar a região demonstra onde o conhecimento é produzido (onde os autores trabalham) e onde ele é veiculado de forma prioritária.

TABELA 5 - Divisão por região a qual os autores têm vínculo institucional

\begin{tabular}{|c|c|c|c|c|c|}
\hline Região & SciELO & $\begin{array}{l}\text { BVS-Psi } \\
\text { (LILACS) }\end{array}$ & $\begin{array}{l}\text { Periódico } \\
\text { CAPES }\end{array}$ & Total & $\%$ \\
\hline Centro-Oeste & - & 2 & - & 2 & $6,06 \%$ \\
\hline Nordeste & - & 1 & 3 & 4 & $12,12 \%$ \\
\hline Norte & - & 1 & - & 1 & $3,03 \%$ \\
\hline Sudeste & 14 & 9 & 3 & 26 & $78,78 \%$ \\
\hline Sul & - & - & - & - & $0 \%$ \\
\hline Total & 14 & 13 & 6 & 33 & $100 \%$ \\
\hline
\end{tabular}


Percebe-se que o Sudeste é a região onde se concentram não apenas a maioria das publicações $(78,94 \%)$, mas também dos autores (e, assim, as instituições que mais publicam), com 78,78\%. Esses dados demonstram dois aspectos: em primeiro lugar, existe uma concentração de veículos e pesquisadores na região Sudeste; o segundo aspecto é que o conhecimento produzido primariamente em uma só região, chegando a ter mais da metade das publicações sobre o tema, tende a descrever e a investigar uma parte do fenômeno, com as outras realidades do Brasil passando à margem da discussão. Sabe-se que nosso país é extenso não só em território, mas em realidades socioculturais, e isso se traduz em uma heterogeneidade que a concentração de publicações não consegue abranger.

Tem-se hoje uma realidade de grande mobilidade no setor da educação, resultado da grande expansão do ensino superior, e a massificação da internet, que facilitou a divulgação da informação. Entretanto, onde se produz o conhecimento e o local onde é veiculado é ponto nodal por dois aspectos: o plano pedagógico e a orientação teórica da instituição (ou dos que a compõem), e a linha editorial do veículo em que é publicado.

Esse quadro se agrava quando se analisa a Tabela 6 , em que se pode ver que todas as publicações levantadas têm como natureza a pesquisa empírica. Nesse caso, os textos não têm como dar conta de uma realidade distante da região onde foram produzidos. Comparando-se as Tabelas 4, 5 e 6, percebeu-se que na região Sul apenas um trabalho sobre o tema foi desenvolvido, fruto de um texto de pós-graduação (a nível de mestrado profissional). A região Norte teve apenas duas publicações, sendo um texto de pós-graduação (tese de doutorado) e um artigo.

A distância geográfica entre o Sudeste, região com maior número de publicações e pesquisadores, e as demais regiões é um indício de que o tema não está sendo tratado na multiplicidade em que um país com diversas características como o nosso precisa, uma vez que só se consegue pesquisar uma realidade entrando em contato com ela.

TABELA 6 - Divisão por natureza da pesquisa

\begin{tabular}{lccc}
\multicolumn{1}{c}{ Portal } & Empírica & Teórica & Total \\
SciELO & 3 & - & 3 \\
BVS-Psi (LILACS) & 6 & - & 6 \\
Periódico CAPES & 3 & - & 3 \\
Banco de Teses da CAPES & 7 & - & 7 \\
Total & 19 & - & 19
\end{tabular}

Utilizando a divisão de tipo de pesquisa estabelecida por Breakwell, Hammond, Fife-Schaw e Smith (2010), as publicações foram classificadas pelo tipo de tratamento que os dados receberam, nesse caso: quantitativo, qualitativo ou quanti-qualitativo. Percebeu-se que a ampla maioria dos textos $(68,42 \%)$ se deteve em uma análise qualitativa, indicando uma grande preocupação em investigar em profundidade os significados dados pelos trabalhadores sobre o fenômeno estudado (Breakwell et al., 2010; Bauer e Gaskell, 2002), conforme demonstra a Tabela 7 .

TABELA 7 - Divisão por tipo de tratamento dos dados

\begin{tabular}{|c|c|c|c|c|c|c|}
\hline Tratamento dos dados & SciELO & $\begin{array}{l}\text { BVS-Psi } \\
\text { (LILACS) }\end{array}$ & $\begin{array}{c}\text { Periódico } \\
\text { CAPES }\end{array}$ & $\begin{array}{c}\text { Banco de } \\
\text { Teses da } \\
\text { CAPES }\end{array}$ & Total & $\%$ \\
\hline Quantitativa & 2 & 2 & - & 1 & 5 & $26,31 \%$ \\
\hline Qualitativa & - & 4 & 3 & 6 & 13 & $68,42 \%$ \\
\hline Quanti-Quali & 1 & - & - & - & 1 & $5,26 \%$ \\
\hline Total & 3 & 6 & 3 & 7 & 19 & $100 \%$ \\
\hline
\end{tabular}

A concentração de publicações em uma só região é agravada pelo tipo de tratamento dos dados da pesquisa. O tratamento quantitativo proporciona ao pesquisador uma grande abrangência geográfica pela padronização e impessoalidade do instrumento que aplica (formulário ou questionário); para uma pesquisa qualitativa, essa 
premissa não pode ser sustentada, pois o contato do pesquisador com o entrevistado é fundamental, principalmente porque a condução da entrevista e os maneirismos envolvidos nessa relação são dados que afetam o resultado que dela pode-se extrair. Apesar isso, conforme salientado, a concentração de produções em apenas uma região não se substanciará em uma correta apreensão das várias facetas do trabalho e da precarização presente no país como um todo.

Nas Tabelas 8 e 9 pode-se ver a divisão de área do conhecimento dos textos e a formação de graduação dos autores. Para esse propósito foi utilizada a classificação adotada de forma oficial e ampla no país, a da CAPES (2012). Dessa forma, tem-se como grande área e subáreas:

1. Grande Área: Saúde Coletiva; Subárea: Saúde Pública;

2. Grande Área: Engenharia da Produção; Subárea: Higiene e Segurança do Trabalho;

3. Grande Área: Interdisciplinar; Subárea: Meio ambiente e Agrárias;

4. Grandes Áreas: Planejamento Urbano e Regional; Administração; Engenharia da Produção; Fisioterapia e Terapia Ocupacional; Psicologia e Serviço Social.

TABELA 8 - Divisão por área do conhecimento das publicações

\begin{tabular}{|c|c|c|c|c|c|c|}
\hline Áreas & SciELO & $\begin{array}{l}\text { BVS-Psi } \\
\text { (LILACS) }\end{array}$ & $\begin{array}{l}\text { Periódico } \\
\text { CAPES }\end{array}$ & $\begin{array}{c}\text { Banco de Teses } \\
\text { da CAPES }\end{array}$ & Total & $\%$ \\
\hline Administração & - & - & - & 1 & 1 & $5,26 \%$ \\
\hline Engenharia de Produção & 1 & - & - & 1 & 2 & $10,52 \%$ \\
\hline Fisioterapia e terapia ocupacional & 1 & - & - & - & 1 & $5,26 \%$ \\
\hline Interdisciplinar & - & - & - & 1 & 1 & $5,26 \%$ \\
\hline Planejamento Urbano e Regional & - & - & - & 1 & 1 & $5,26 \%$ \\
\hline Psicologia & - & 2 & - & - & 2 & $10,52 \%$ \\
\hline Saúde Coletiva & 1 & 4 & 3 & 2 & 10 & $52,62 \%$ \\
\hline Serviço Social & - & - & - & 1 & 1 & $5,26 \%$ \\
\hline Total & 3 & 6 & 3 & 7 & 19 & $100 \%$ \\
\hline
\end{tabular}

Percebe-se que é na área de Saúde Coletiva que os artigos sobre o tema encontram maior espaço de publicação, e que os periódicos na área da Psicologia tiveram apenas dois artigos publicados em cinco anos, um número muito pequeno para um campo do conhecimento que tem uma área específica para estudar esse tipo de fenômeno, principalmente quando se considera que essa é uma das mais antigas na Psicologia, com revistas específicas sobre o campo. Esse fato também pode ser atribuído à natureza dessa área: é multidisciplinar e por ela transitam pesquisadores de diversas formações, entre eles enfermeiros, sociólogos, médicos e fisioterapeutas, conforme podemos ver na Tabela 9.

TABELA 9 - Divisão por área de formação dos autores

\begin{tabular}{|c|c|c|c|c|c|c|}
\hline Área & SciELO & $\begin{array}{l}\text { BVS-Psi } \\
\text { (LILACS) }\end{array}$ & $\begin{array}{l}\text { Periódico } \\
\text { CAPES }\end{array}$ & $\begin{array}{c}\text { Banco de Teses da } \\
\text { CAPES }\end{array}$ & Total & $\%$ \\
\hline Administração & - & 1 & - & 1 & 2 & $5 \%$ \\
\hline Biologia & - & - & 1 & - & 1 & $2,5 \%$ \\
\hline Ciências & - & - & 1 & - & 1 & $2,5 \%$ \\
\hline Ciências Sociais & 2 & - & - & - & 2 & $5 \%$ \\
\hline Comunicação Social & - & - & - & 1 & 1 & $2,5 \%$ \\
\hline Direito & 1 & - & - & - & 1 & $2,5 \%$ \\
\hline
\end{tabular}




\begin{tabular}{|c|c|c|c|c|c|c|}
\hline Enfermagem & 1 & 4 & 3 & - & 8 & $20 \%$ \\
\hline Engenharia Mecânica & 2 & - & - & - & 2 & $5 \%$ \\
\hline Fonoaudiologia & 2 & 2 & - & - & 4 & $10 \%$ \\
\hline Fisioterapia & 1 & - & - & - & 1 & $2,5 \%$ \\
\hline Medicina & 1 & 1 & - & 2 & 4 & $10 \%$ \\
\hline Psicologia & 2 & 4 & - & 2 & 8 & $20 \%$ \\
\hline Serviço Social & - & - & 1 & 1 & 2 & $5 \%$ \\
\hline Sociologia & - & 1 & - & - & 1 & $2,5 \%$ \\
\hline Não informado & 2 & - & - & - & 2 & $5 \%$ \\
\hline Total & 14 & 13 & 6 & 7 & 40 & $100 \%$ \\
\hline
\end{tabular}

Psicologia e Enfermagem têm o maior número de autores, 20\% cada uma, seguido de Fonoaudiologia e Medicina, com 10\% cada. A formação dos autores é importante para um estudo como este, porque não só mostra uma distribuição simples por área do conhecimento, mas apresenta um recorte de como o fenômeno é encarado, pois se sabe que a formação do pesquisador delimita em certo aspecto a forma como ele conduz suas pesquisas.

A maior parte dos textos apresenta uma leitura qualitativa dos dados, como apresentado na Tabela 7, e os autores têm formação prioritariamente em áreas de Ciências Humanas e Sociais (ou Sociais Aplicadas, mais especificamente). Esses dados corroboram entre si, pois essas áreas do conhecimento têm maior tendência a produzir estudos dessa natureza.

Um dado importante apresentado na Tabela 9 é que os dois psicólogos que aparecem na base de dados SciELO são o mesmo autor, que teve dois artigos publicados durante o período pesquisado; o mesmo ocorre com os dois engenheiros mecânicos e os dois fonoaudiólogos na mesma base de dados, todos publicaram juntos os dois artigos, o que deve indicar uma rede de pesquisa. Nesse caso, deve-se considerar que o número de psicólogos foi de sete e não de oito, uma vez que o mesmo autor publicou dois artigos no mesmo período. Se em termos de autoria a Psicologia e a Enfermagem permanecem com a mesma quantidade, em variedade de autores a Enfermagem tem um autor a mais, já que nela nenhum deles se repetiu.

Analisa-se como positiva essa variação, principalmente considerando que temos nesse quadro áreas pouco comuns a esse campo de pesquisa, como a Engenharia Mecânica e o Direito. Isso é importante, pois o trabalho é uma categoria que atravessa a vida do sujeito em várias instâncias e, por isso, está sujeita a diversas interfaces e intervenções. Da mesma forma que leis são criadas e modificadas sobre as condições, os direitos e os deveres desses trabalhadores, a confluência de áreas do conhecimento tão distintas contribui para ressaltar o dinamismo e complexidade do campo, o que tende a ser vista com bons olhos.

\section{DISCUSSÃO}

Conforme destacado nesta pesquisa, o país vem passando, desde o início da década de 1990, por um processo de precarização do trabalho, o que gerou uma expansão do mercado informal. O crescimento econômico pelo qual o país passa desde então, devido, entre outros fatores, à abertura comercial e à injeção de investimentos estrangeiros, caminha no sentido contrário à garantia de direitos mínimos de trabalho no mercado brasileiro. $\mathrm{Na}$ busca por menores custos no processo produtivo e maior inserção da economia brasileira em setores importantes da economia internacional, é a força de trabalho que sofre os maiores vilipêndios por meio da expansão de contratos precários, piores condições de trabalho e ausentes representações sindicais.

Marcado pela degradação evidente das condições e garantias de trabalho, o ano de 2015 pode vir a ser um marco no processo de precarização da classe trabalhadora por meio do estabelecimento da terceirização enquanto ferramenta legal de tratamento dos trabalhadores pelo empresariado. O Projeto de Lei 4.330/2004 (2004) e as Medidas Provisórias 664 (2014) e 665 (2014) representam, assim, a normalização de uma situação 
sempre camuflada de aviltamento das condições de trabalho, que, por sua vez, abre espaço para processos de degradação mais fortes sobre o trabalho, tal como vem se manifestando a "quarteirização".

Este trabalho buscou traçar um panorama acerca da produção sobre a terceirização e a saúde do trabalhador, entendendo esta última como uma das inúmeras consequências do processo de terceirização. Infelizmente, os estudos que envolvem a terceirização e seu nexo causal para com a saúde do trabalhador, entendendo-a como um processo de vulnerabilização do indivíduo que ultrapassa o campo do trabalho e se estende para as relações sociais mais amplas, além de serem escasssos, são concentrados nas áreas de maior movimentação econômica, restringindo o campo de visão dos pesquisadores envolvidos a condições características das zonas mais economicamente ativas e desenvolvidas do país.

Tal limitação encobre as diferenciações, os diversos "Brasis" existentes. A ausência de mais trabalhos sobre a temática, e também de trabalhos mais diversos em relação às regiões e aos estados nos quais são produzidos, reforça o nível de abjeção à qual o processo de terceirização pode levar os trabalhadores da contemporaneidade. Por sua vez, a defesa do processo como ferramenta-chave no aumento da empregabilidade no país não leva em consideração a degradação das garantias trabalhistas e a rotatividade no trabalho, que deverá aumentar muito, gerando uma condição de instabilidade em massa, de menores salários e piores condições de trabalho, que, por sua vez, gerarão uma piora considerável na saúde do indivíduo (seja pela diminuição dos salários, que vulnerabilizam a qualidade de vida do indivíduo por meio do acesso a outro patamar de consumo, educação e informação, seja pela constante pressão em ser demitido).

Apesar da escassez de trabalhos científicos sobre o tema durante os cinco últimos anos no Brasil, espera-se que, com a atual discussão acerca das leis que envolvem o processo de terceirização e os recorrentes casos de mortes e adoecimentos no espaço de trabalho, o debate faça emergir o cuidado pelas condições de saúde e bemviver da população trabalhadora e a situação de vulnerabilidade multifocal a qual está exposta enquanto fortes contrapontos ao crescimento econômico, que, na estrutura social brasileira, apenas geram maior concentração e desigualdade.

\section{REFERÊNCIAS}

Antunes, R. (1999). Os sentidos do trabalho: Ensaio sobre a afirmação e a negação do trabalho. São Paulo: Boitempo.

Antunes, R. (2015, 9 de abril). Entrevista a Esquerda Diário. Não se deve jamais regulamentar a terceirização, mas impedi-la. Recuperado de www.esquerdadiario.com.br/Ricardo-Antunes-Nao-se-deve-jamais-regulamentar-a-terceirizacao-masimpedi-la

Aquino, C. A. B., Moita, D. S., Correa, G. M., \& Souza, K. O. (2014). O fenômeno da precarização e da flexibilização laboral no âmbito da universidade pública brasileira: $\mathrm{O}$ caso dos professores substitutos. Athenea Digital: Revista de Pensamiento e Investigación Social, 14(1), 173-193. doi: http://dx.doi.org/10.5565/rev/athenead/v14n1.1004.

Bauer, M.W., \& Gaskell, G. (2002). Pesquisa qualitativa com texto, imagem e som: Um manual prático. Petrópolis: Vozes.

Borsói, I. (2011). Vivendo para trabalhar: Do trabalho degradado ao trabalho precarizado. Convergencia, 18(55), 113-133.

Breakwell, G. M., Hammond, S., Fife-Schaw, C., \& Smith, J. A. (2010). Métodos de pesquisa em psicologia (3a ed.). Porto Alegre: Artmed.

Canguilhem, G. (2009). O normal e o patológico (6a ed.) Rio de Janeiro: Forense Universitária.

Castel, R. (1997). A dinâmica dos processos de marginalização: Da vulnerabilidade a "desfiliação". Caderno CRH, 10(26), $19-40$.

Castel, R. (2008). As metamorfoses da questão social: Uma crônica do salário (7a ed.) Petrópolis: Vozes.

Coordenação de Aperfeiçoamento de Pessoal de Ensino Superior. (2012). Tabela de áreas do conhecimento. Recuperado de http://www.capes.gov.br/avaliacao/instrumentos-de-apoio/tabela-de-areas-do-conhecimento-avaliacao

Dejours, C. (1999). A banalização da injustiça social. Rio de Janeiro: Fundação Getúlio Vargas

Departamento Intersindical de Estatística e Estudos Socioeconômicos \& Universidade Estadual de Campinas. (2007). Aspectos conceituais e metodológicos da vulnerabilidade social. Brasília: Ministério do Trabalho e Emprego.

Dumazedier, J. (2008). Sociologia empírica do lazer (3a ed.). São Paulo: Perspectiva.

Elias, N. (1994). A sociedade dos indivíduos. Rio de Janeiro: Jorge Zahar.

Garcia, L. P. (2014). Revisão sistemática da literatura e integridade na pesquisa. Epidemiologia e Serviços de Saúde, 23(1), 7-8. doi: 10.5123/S1679-49742014000100001 
Jorge, M. S. B., \& Bezerra, M. L. M. R. (2004). Inclusão e exclusão social do doente mental no trabalho: Representações sociais. Texto \& Contexto - Enfermagem, 13(4), 551-558. doi: http://dx.doi.org/10.1590/S0104-07072004000400007

Lacaz, F. A. C. (2007). O campo saúde do trabalhador: Resgatando conhecimentos e práticas sobre as relações trabalho-saúde. Cadernos de Saúde Pública, 23(4), 757-766. doi: http://dx.doi.org/10.1590/S0102-311X2007000400003

Landeiro, G. M. B., Pedrozo, C. C. R., Gomes, M. J., \& Oliveira, E. R. A. (2011). Revisão sistemática dos estudos sobre qualidade de vida indexados na base de dados SciELO. Ciência \& Saúde Coletiva, 16(10), 4257-4266. doi: http://dx.doi.org/10.1590/ S1413-81232011001100031

Lima, S. M. (2011). Produção de conhecimento sobre a tríade saúde, trabalho e subjetividade. In C. Minayo-Gomez, J. M. H. Machado \& P. G. L. Pena (Orgs.), Saúde do trabalhador na sociedade brasileira contemporânea (pp. 315-324). Rio de Janeiro: Fiocruz.

Lima, C. A., Barros, E. M. C., \& Aquino, C. A. B. (2012). Flexibilização e intensificação laboral: Manifestações da precarização do trabalho e suas consequências para o trabalhador. Revista Labor, 1(7), 102-125.

Lipovetsky, G. (2005). A era do vazio: Ensaios sobre o individualismo contemporâneo. Barueri: Manole.

Marcelino, P. R. P. (2008). Terceirização e ação sindical: A singularidade da reestruturação do capital no Brasil (Tese de doutorado). Recuperado de http://www.bibliotecadigital.unicamp.br/document/?code=vtls000438166

Medida Provisória no 664 de 30 de dezembro de 2014 (2014, 30 dezembro). Altera as Leis no 8.213, de 24 de julho de 1991, no 10.876, de 2 junho de 2004, no 8.112, de 11 de dezembro de 1990, e a Lei no 10.666, de 8 de maio de 2003. Recuperado de http://www.planalto.gov.br/ccivil_03/_Ato2011-2014/2014/Mpv/mpv664.htm

Medida Provisória no 665 de 30 de dezembro de 2014 (2014, 30 dezembro). Altera a Lei no 7.998, de 11 de janeiro de 1990, que regula o Programa do Seguro-Desemprego, o Abono Salarial e institui o Fundo de Amparo ao Trabalhador - FAT, altera a Lei no 10.779, de 25 de novembro de 2003, que dispõe sobre o seguro desemprego para o pescador artesanal, e dá outras providências. Recuperado de http://www.planalto.gov.br/ccivil_03/_ato2011-2014/2014/mpv/mpv665.htm

Minayo-Gomez, C., \& Brant, L. C. (2011). A temática do sofrimento nos estudos sobre trabalho e saúde. In C. Minayo-Gomez, J. M. H. Machado \& P. G. L. Pena (Orgs.), Saúde do trabalhador na sociedade brasileira contemporânea (pp. 385-408). Rio de Janeiro: Fiocruz.

Minayo-Gomez, C., \& Thedim-Costa, S. M. F. (1997). A construção do campo da saúde do trabalhador: Percurso e dilemas. Cadernos de Saúde Pública, 13(2), 21-32. doi: http://dx.doi.org/10.1590/S0102-311X1997000600003

Munnè, F. (1990). Psicosociologia del tiempo libre: Un enfoque critico. Mexico: Trillas.

Navarro, V. L., \& Padilha, V. (2007). Dilemas do trabalho no capitalismo contemporâneo. Psicologia \& Sociedade, 19(número especial), 14-20. doi: http://dx.doi.org/10.1590/S0102-71822007000400004

Projeto de Lei n. 4330, de 26 de outubro de 2004 (2004, 24 de abril). Dispõe sobre o contrato de prestação de serviço a terceiros e as relações de trabalho dele decorrentes. Recuperado de http://www.camara.gov.br/proposicoesWeb/fichadetramitacao?i dProposicao $=267841$

Pronovost, G. (2011). Introdução à sociologia do lazer. São Paulo: Senac.

Secretaria Nacional de Relações de Trabalho \& Departamento Intersindical de Estatística e Estudos Socioeconômicos (SRT/ DIEESE). (2014). Terceirização e desenvolvimento: Uma conta que não fecha. Dossiê acerca do impacto da terceirização sobre os trabalhadores e propostas para garantir a igualdade de direitos. São Paulo: CUT. Recuperado de http://www.cut. org.br/system/uploads/ck/files/Dossie-Terceirizacao-e-Desenvolvimento.pdf

Torres, A. R. A., Chagas, M. I. O., Moreira, A. C. A., Barreto, I. C. H. C., \& Rodrigues, E. M. (2011). O adoecimento no trabalho: Repercussões na vida do trabalhador e de suas famílias. SANARE, 10(1), 42-48.

Weber, M. (2015). A ética protestante e o espírito do capitalismo (2a ed.). São Paulo: Thomson Pioneira. 